\title{
Equatorial Spread F structures and associated airglow intensity variations observed over Gadanki
}

\author{
R. Sekar ${ }^{1}$, D. Chakrabarty ${ }^{1}$, R. Narayanan ${ }^{1}$, and A. K. Patra ${ }^{2}$ \\ ${ }^{1}$ Physical Research Laboratory, Ahmedabad, India \\ ${ }^{2}$ National Atmospheric Research Laboratory, Gadanki, India
}

Received: 3 July 2008 - Revised: 25 August 2008 - Accepted: 21 October 2008 - Published: 2 December 2008

\begin{abstract}
Co-ordinated campaigns have been conducted from Gadanki $\left(13.5^{\circ} \mathrm{N}, 79.2^{\circ} \mathrm{E}\right.$, dip lat $\left.6.4^{\circ} \mathrm{N}\right)$ by operating simultaneously the Indian MST radar in ionospheric coherent backscatter mode and by monitoring thermosphere airglow line emissions $(630.0 \mathrm{~nm}$ and $777.4 \mathrm{~nm})$ using a narrow band multi-wavelength scanning photometer during JanuaryMarch for the past five years (2003-2007) and also during April 2006, as a special campaign. Simultaneous radar and optical observations reveal optical signatures corresponding to a variety of equatorial spread $F$ (ESF) structures. The optical signatures corresponding to ESF structures with wavelike bottomside modulations with plasma plumes, confined bottomside flat and wavelike structures, vertically extended plume structure in the absence of bottomside structure apart from the classical plasma depletions and enhancements are obtained during these campaigns. The plasma depletions and enhancements were identified using optical measurements. In addition, estimations of zonal wavelength of the bottomside structures and the inference of shears in the zonal plasma drift in the presence of confined structures, were carried out using bi-directional airglow measurements. Furthermore, it is found that the vertical columnar intensity of OI $630.0 \mathrm{~nm}$ airglow exceeded the slanted columnar intensity in the presence of large bottomside structure. The need for the appropriate physical mechanisms for some of the ESF structures and their characterizations with optical observations are discussed.
\end{abstract}

Keywords. Atmospheric composition and structure (Airglow and aurora) - Ionosphere (Equatorial ionosphere; Ionospheric irregularities)

\footnotetext{
Correspondence to: R. Sekar

(rsekar@prl.res.in)
}

\section{Introduction}

Equatorial spread $\mathrm{F}(\mathrm{ESF})$ is a generic term that refers to the plasma irregularities in the F-region of the ionosphere with scale sizes encompassing from a few hundreds of kilometers to a few centimeters. Several techniques have been used to investigate different spectral regimes of these irregularities. Comparative studies of this phenomenon with different techniques enable to understand ESF more comprehensively. The radars operating in HF, VHF and UHF frequencies have been used to investigate this phenomenon (Kelley, 1989). Among these, VHF radars have been extensively used to investigate the structures and dynamics of the plasma irregularities that are present both in the bottomside and topside of the ionosphere. The ESF structures have been investigated using VHF radar at various longitudinal sectors (Tsunoda, 1980; Patra et al., 1995; Fukao et al., 2004) ever since Woodman and La Hoz (1976) reported various ESF structures over Jicamarca. Comparison of the UHF radar map with the results obtained from rocket borne (Rino et al., 1981) and satellite borne probes (Tsunoda et al., 1982) revealed that the plume structures as seen by the radars are indeed associated with large scale plasma bubbles. A coordinated TEC and VHF radar measurement (Tsunoda and Towle, 1979) revealed that the plumes are found to be coincident with TEC depletions. Similarly, the results obtained using optical imagers was compared with VHF radar results (Mendillo et al., 1992) and also with the digital ionograms (Weber et al., 1996) to get a clue for the onset conditions for the development of plasma depletions. Thus the comparative studies with various techniques are useful in obtaining physical insight of ESF. In the recent past, comparison between the narrow-band optical measurements of thermospheric airglow emissions and the VHF radar measurements revealed the presence of plasma enhancement (Sekar et al., 2004) extending beyond $350 \mathrm{~km}$ and an evidence for fossil bubbles turning active (Sekar et al., 2007) was obtained. In addition,

Published by Copernicus Publications on behalf of the European Geosciences Union. 

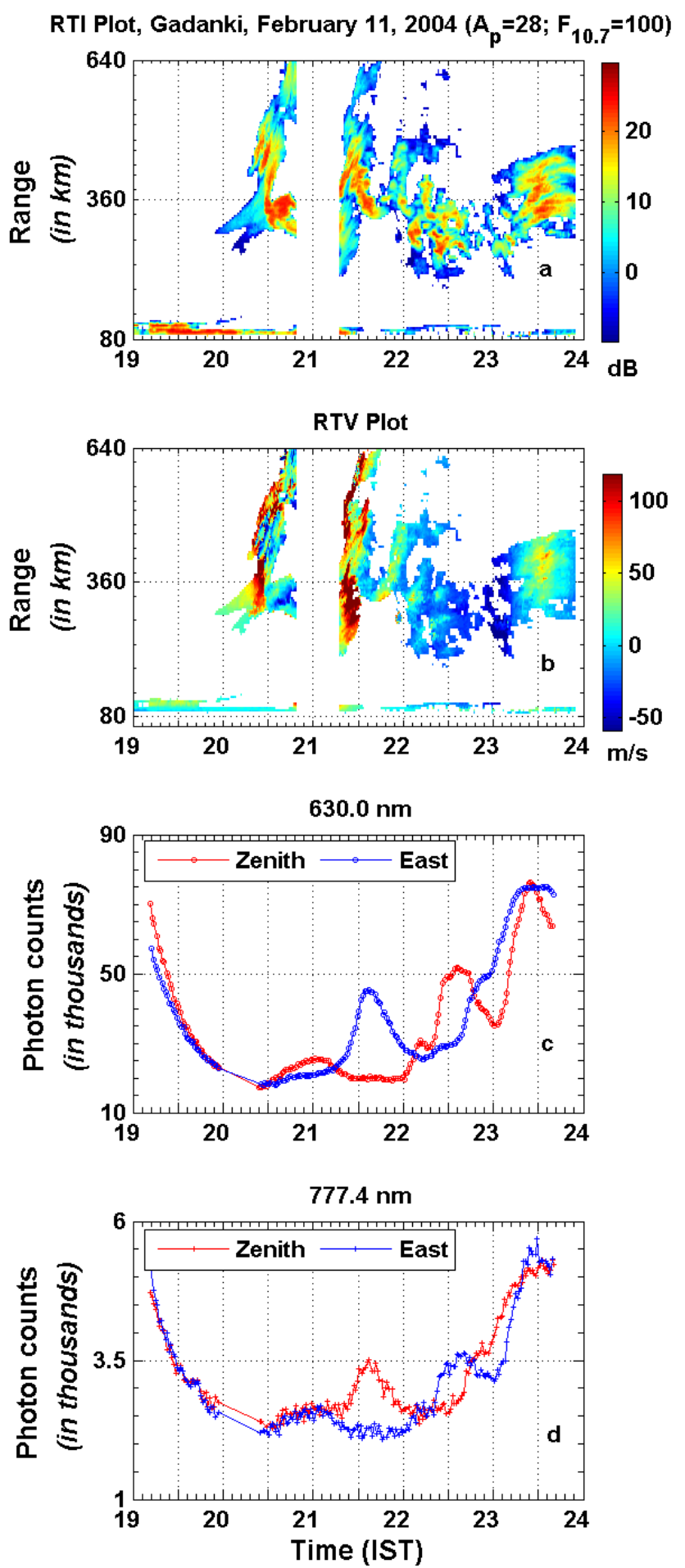

Fig. 1. (a) Range-Time-Intensity (RTI) map of equatorial spread F structures observed over Gadanki on 11 February 2004 revealing wave-like bottomside structure with large altitude extents, (b) the corresponding Range-Time-Velocity (RTV) map, (c) temporal variations of OI $630.0 \mathrm{~nm}$ airglow intensity over zenith (red) and $45^{\circ}$ eastern (blue) directions, (d) temporal variations of OI $777.4 \mathrm{~nm}$ airglow intensity over zenith (red) and $45^{\circ}$ eastern (blue) directions. simultaneous triggering of ESF at two zonally separated locations during storm time was identified (Chakrabarty et al., 2006; Sekar and Chakrabarty , 2008) using bi-directional airglow and VHF radar observations. Results obtained with particular ESF structures were discussed in those studies. In the present paper, optical signatures at $630.0 \mathrm{~nm}$ and $777.4 \mathrm{~nm}$ corresponding to a variety of ESF structures revealed by the VHF radar maps are presented and discussed.

\section{Experimental details}

The mesosphere-stratosphere-troposphere (MST) radar at Gadanki is a high power coherent pulsed radar which operates at $53 \mathrm{MHz}$ with a maximum peak-power-apertureproduct of $3 \times 10^{10} \mathrm{~W} \mathrm{~m}^{2}$. The detailed descriptions of the radar subsystems are discussed by Rao et al. (1995). The observations reported in this communication are obtained using the $3^{\circ}$ wide beam oriented at $14.8^{\circ} \mathrm{N}$ from zenith, which makes the beam normal to Earth's magnetic field at F-region altitudes.

The details of the multi-wavelength scanning photometer for airglow studies during nighttime have been discussed in a previous communication (Sekar et al., 2004). Temperaturetuned, narrow band (band width $\sim 0.3 \mathrm{~nm}$ ) interference filters are used in this photometer. Further, the field of view $\left(\sim 3^{\circ}\right)$ of the photometer is chosen to be similar to the VHF radar beamwidth. The photometer was operated in a bidirectional mode using a computer-controlled mirror scanning arrangement fitted on top of the photometer. Coordinated airglow and radar measurements have been conducted in campaign modes during January-March 2003-2007 and in April 2006 as a special campaign mode. Note that the integration time is $10 \mathrm{~s}$ for most of the airglow observations except during March 2003 campaign when it is $1 \mathrm{~s}$.

\section{Observations}

Although ESF structures are known to have enormous variabilities from one event to another, the basic structural characteristics observed by VHF radar, however, are found to fall in a few broad categories. Accordingly, observations made during last 5 years have been thoroughly scrutinized and classified. The following examples elicit fairly well that simultaneous VHF radar and airglow observations can be used effectively to characterize different features of ESF. In order to appraise the solar flux and geomagnetic activity conditions, the $F_{10.7}$ and $A_{P}$ indices are provided in the text as well as in figures.

3.1 Wave-like bottomside ESF structure with large altitude extents

Figure 1 depicts the results obtained from both the VHF radar and airglow photometer on 11 February 2004 which happens 
to be a magnetically disturbed day $\left(A_{P}=28, F_{10.7}=100\right)$. The time in IST (Indian Standard Time, IST $=$ Universal Time, $\mathrm{UT}+5.5 \mathrm{~h}$ ) is plotted along abscissa which is common for all the subplots. The Range-Time-Intensity (RTI) and RangeTime-Velocity (RTV) maps of the radar echoes are shown in subplots $1 \mathrm{a}$ and $1 \mathrm{~b}$, respectively. The colour codes in them correspond to SNR (in $\mathrm{dB}$ ) of return echoes in panel (a) and line-of-sight Doppler velocities in panel (b). The vertical and slant (along east $45^{\circ}$ ) columnar intensities of $630.0 \mathrm{~nm}$ and $777.4 \mathrm{~nm}$ airglow emissions are depicted in panels (c) and (d), respectively, in Fig. 1. Similar panels are used in all the remaining figures. Note that there are gaps in radar data (in Fig. 1) during 20:50-21:20 IST and in photometer data during 19:50-20:30 IST due to technical reasons. The RTI map in Fig. 1a reveals a wave like bottomside undulation along with vertically erect and slant plume structures. The bottomside undulation encompassed from $\sim 225 \mathrm{~km}$ to as high as $\sim 350 \mathrm{~km}$ altitude region. The temporal variations of $630.0 \mathrm{~nm}$ airglow intensities observed from zenith (continuous curve) and east (dotted) reveal monotonic decrease during post-sunset hours followed by large (period $>1.0 \mathrm{~h}$ ) and small scale (period $\sim 30 \mathrm{~min}-1.0 \mathrm{~h}$ ) variations. The small scale variations are not prominent in slant columnar intensity while large scale variations are prominent in both directions. It is interesting to note that the integrated slant columnar intensity is less than vertical columnar intensity on occasions. The temporal variations of $630.0 \mathrm{~nm}$ along zenith direction depicted in Fig. 1c, reveal a large scale enhancement between 21:15 to 22:00 IST. Corresponding to this time interval, the integrated intensity over slant columnar intensity is found to be less. An enhancement is observed at a displaced time interval for the slant columnar intensity variation depicted as dotted profile in Fig. 1c. Comparing Fig. 1c and d, it is clear that $777.4 \mathrm{~nm}$ intensity variations over zenith during $21: 15$ 23:00 IST are anti-correlated with the intensity variations of $630.0 \mathrm{~nm}$ over zenith. During the same time interval, the intensity variation of $777.4 \mathrm{~nm}$ over east is found to be correlated with the intensity variation of $630.0 \mathrm{~nm}$ over zenith. A similar correlation is also observed between the intensity variations of $777.4 \mathrm{~nm}$ over zenith with $630.0 \mathrm{~nm}$ over east.

Figure 2 depicts another example of large altitude extent of bottomside structure associated with ESF observed on another magnetically disturbed day (7 February 2005; $A_{P}=30, F_{10.7}=90$ ). During 20:00 to 20:30 IST, both bottomside structures and a plume event are seen in the radar map. Correspondingly, over zenith, the airglow intensities in $630.0 \mathrm{~nm}$ reveal a slight increase around 20:30 and and a decrease in 777.4 emission centered around 20:15 IST. After 20:30 IST, the bottomside structures moved well beyond the $630.0 \mathrm{~nm}$ emission layer encompassing the altitude region around $400 \mathrm{~km}$. Correspondingly, the zenith emission intensities in $630.0 \mathrm{~nm}$ and $777.4 \mathrm{~nm}$ reveal flat and oscillatory features, respectively. However, the slant columnar intensity in $630.0 \mathrm{~nm}$ emission revealed a slight enhancement corresponding to this bottomside structure as the lower alti-
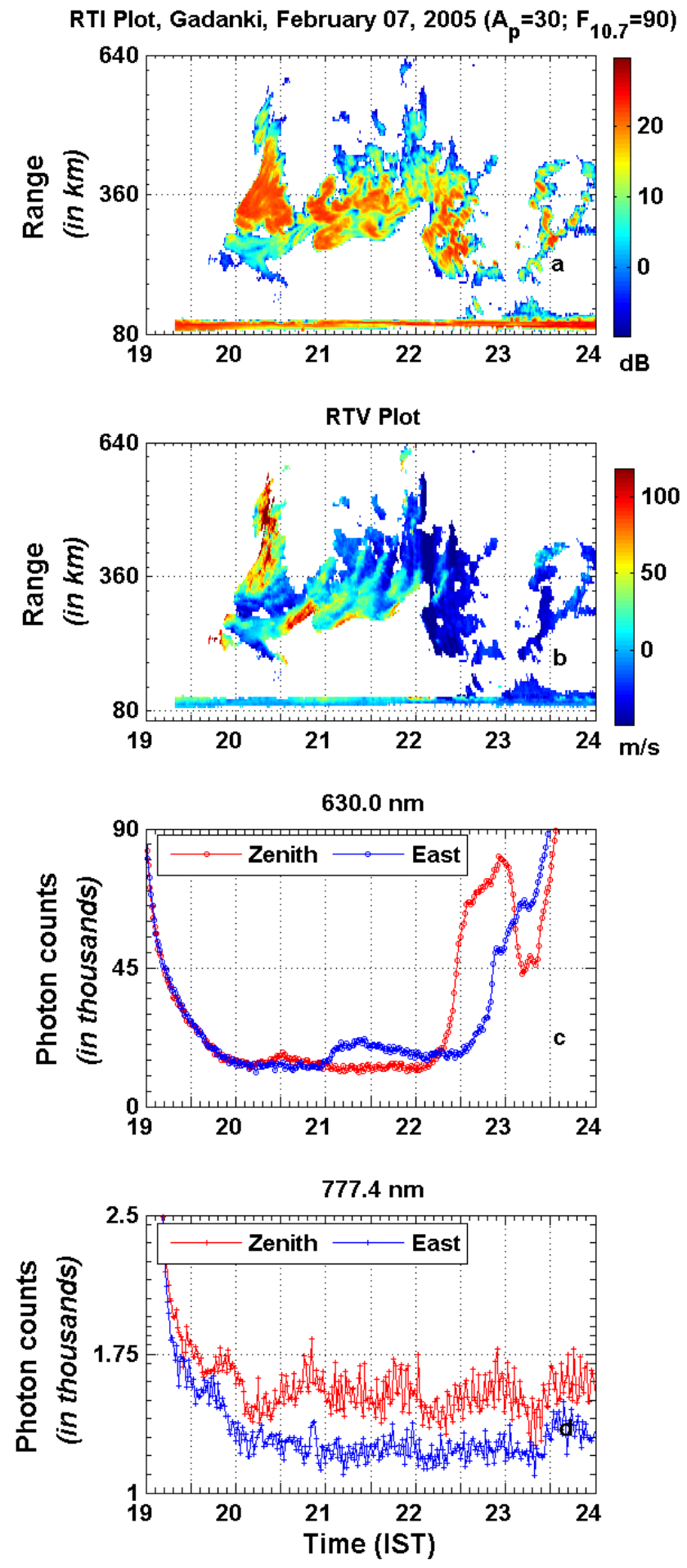

Fig. 2. Similar to Fig. 1 but for 7 February 2005 revealing wave-like bottomside structure with large altitude extents.

tude structures at an earlier time are tracked by the photometer. Around 23:30 IST, a plume structure with corresponding decreases in $630.0 \mathrm{~nm}$ and $777.4 \mathrm{~nm}$ is observed. 

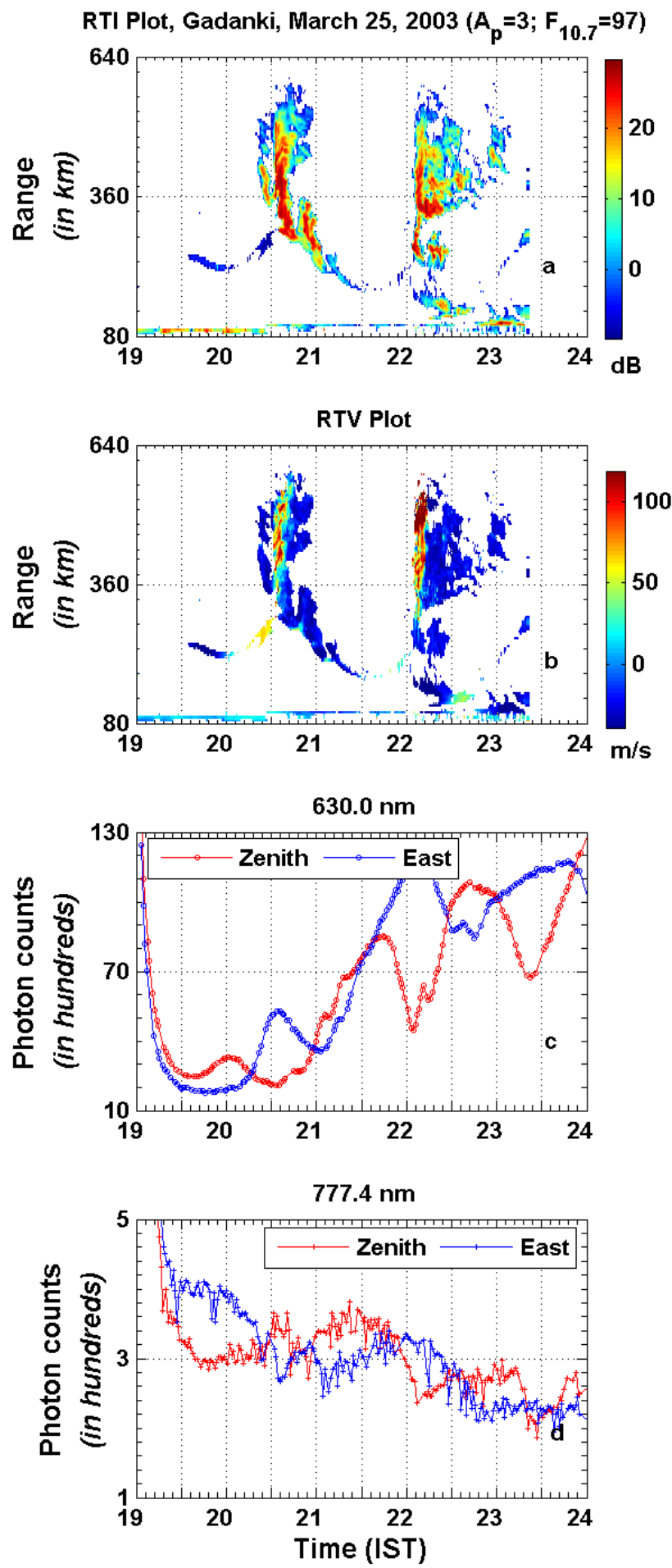

Fig. 3. Similar to Fig. 2 but for 25 March 2003 revealing wavelike bottomside structure with large altitude extents. Note that the integration time for airglow observations is $1 \mathrm{~s}$.

Figure 3 depicts yet another example of ESF structure on 25 March 2003 having a spectacularly sinusoidal bottomside structure with large altitude extent. It is noted that, unlike the previous two cases, this day was magnetically quiet $\left(A_{P}=3\right.$, $\left.F_{10.7}=97\right)$. The detailed description of this structure in comparison with the observation on non ESF night along with the corresponding airglow signatures in the vertical direction have been discussed in a previous communication (Sekar et al., 2004). Some of the plume structures were shown to be plasma enhancements (Sekar et al., 2004). However, the airglow observations in the eastward $\left(45^{\circ}\right.$ elevation) direction were not considered earlier and are included in Fig. $3 \mathrm{c}$ and d, respectively. The bi-directional airglow observations are also used in determining the zonal plasma drift and in deciphering the zonal wavelength (discussed later) of the bottomside structure.

3.2 Bottomside confinement of ESF structures and associated airglow intensity variations

Figure 4 depicts an ESF event where only bottomside ESF structure is observed without any plasma plume. This observation is on 19 March $2004\left(A_{P}=7, F_{10.7}=100\right)$ which happens to be magnetically quiet day preceded by quiet conditions for a few days. In Fig. 4a, the RTI map reveals that ESF structures are confined around $250-300 \mathrm{~km}$. The RTV map in Fig. $4 \mathrm{~b}$ brings out the upward moving region flanked by downward moving regions in that confined structure. Corresponding to this structure, a weak response is seen only in $630.0 \mathrm{~nm}$ airglow intensity variations as depicted in Fig. 4c. It is interesting to note that the vertical columnar intensity during 19:45 to 20:15 IST is more than the slant columnar intensity. A steep rise in $630.0 \mathrm{~nm}$ intensity is observed in both vertical and slant columnar intensities at around 20:45 IST and at 20:15 IST respectively. The turning points in the temporal variations of $630.0 \mathrm{~nm}$ intensities over eastern direction are preceding the zenith observations indicating that the structures are moving westward. In the absence of high altitude structures (like plumes), no significant intensity variation is observed in $777.4 \mathrm{~nm}$ (Fig. 4d) except a few spikes for which the reasons are not understood.

Figure 5 depicts a similar set of subplots for another case of ESF that occurred on 21 March $2004\left(A_{P}=11\right.$, $\left.F_{10.7}=99\right)$. Figure 5a reveals a wavelike bottomside structure confined between $250-300 \mathrm{~km}$ during time interval of 20:00 to 21:30 IST. A trough in the bottomside structure with a very slanted plume is seen around 20:45 to 21:00 IST. However, a couple of vertically erect plume structures extending upto $380 \mathrm{~km}$ are also noticed around 22:00 IST. The RTV plot in Fig. $5 \mathrm{~b}$ reveals downward velocity in the vertically elongated plume structures as well as in the slanted plume. An increase in $630.0 \mathrm{~nm}$ emission intensity is noticed in zenith observation corresponding to the trough in the bottomside structure around 20:45 IST which is evident in Fig. 5c. Depletion and enhancement in $630.0 \mathrm{~nm}$ zenith intensity around 21:45 IST and 22:00 IST, respectively, are observed where there are crest and trough in the bottomside structure, respectively. The turning points in the temporal variations of $630.0 \mathrm{~nm}$ 

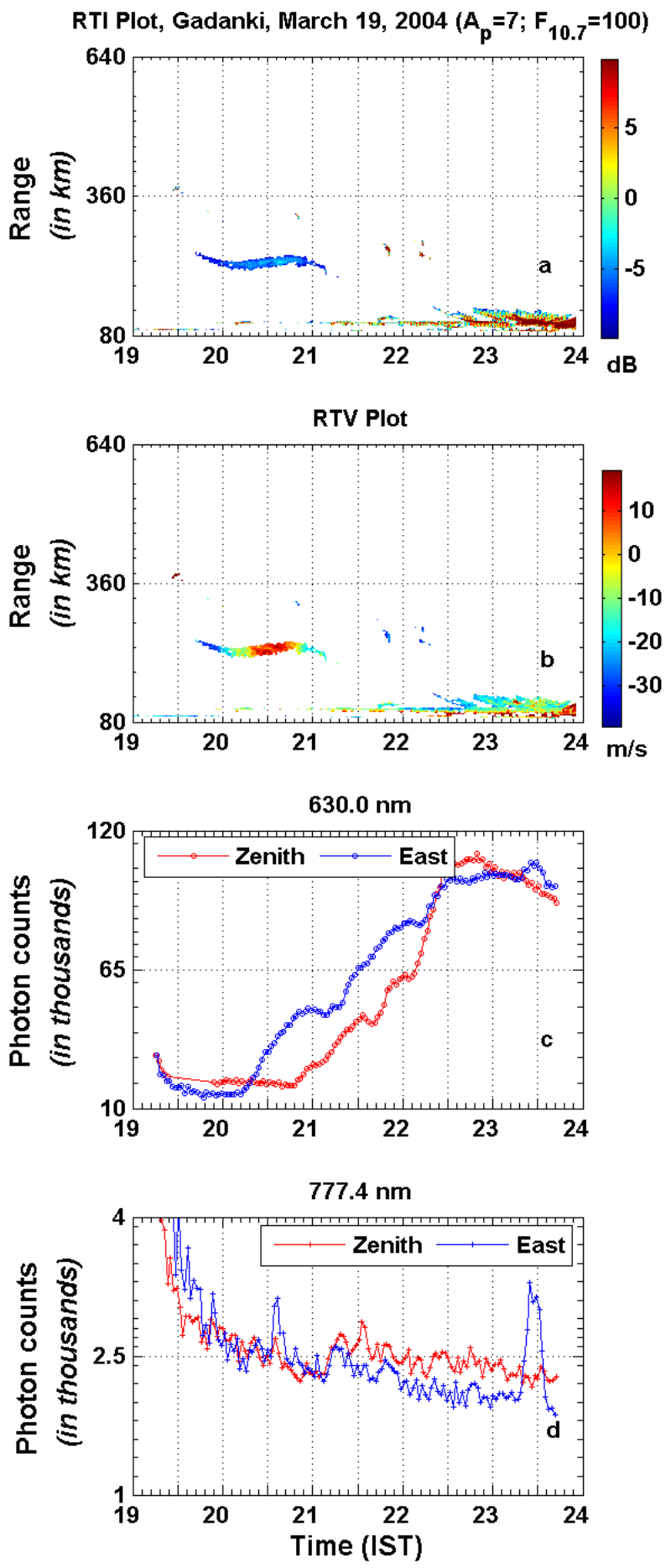

Fig. 4. Similar to Fig. 3 but for 19 March 2004 revealing bottomside confinement of ESF structures and associated airglow intensity variations.

intensity over zenith and eastward directions around 20:45 and 21:00 IST suggest that the zonal drift is eastward around 250-300 km altitude region. Unlike the previous case, the shears in the zonal drift could not be directly inferred for
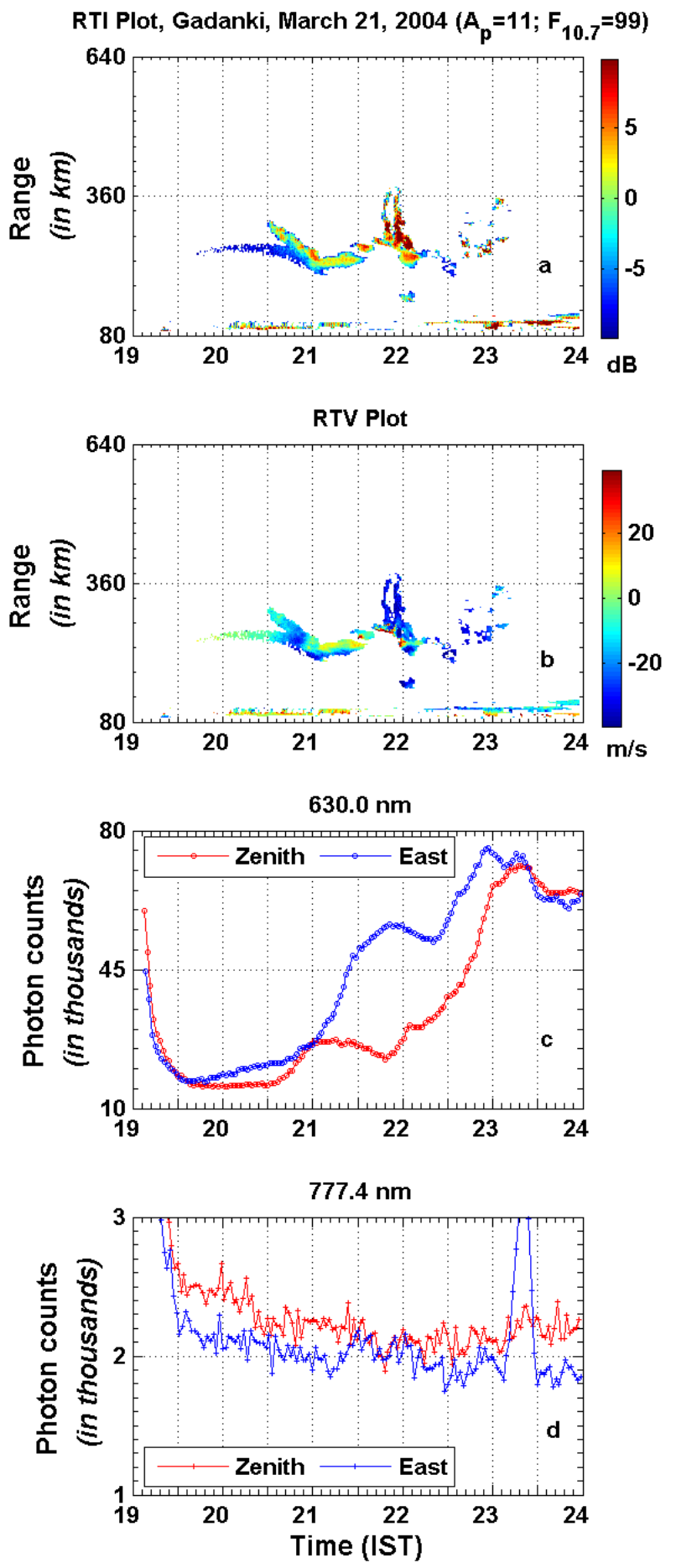

Fig. 5. Similar to Fig. 4 but for 21 March 2004 revealing bottomside confinement of ESF structures and associated airglow intensity variations.

this case. No discernible response is observed in $777.4 \mathrm{~nm}$ intensity variation (barring a spike similar to Fig. 4d) corresponding to ESF structures (Fig. 5d). 

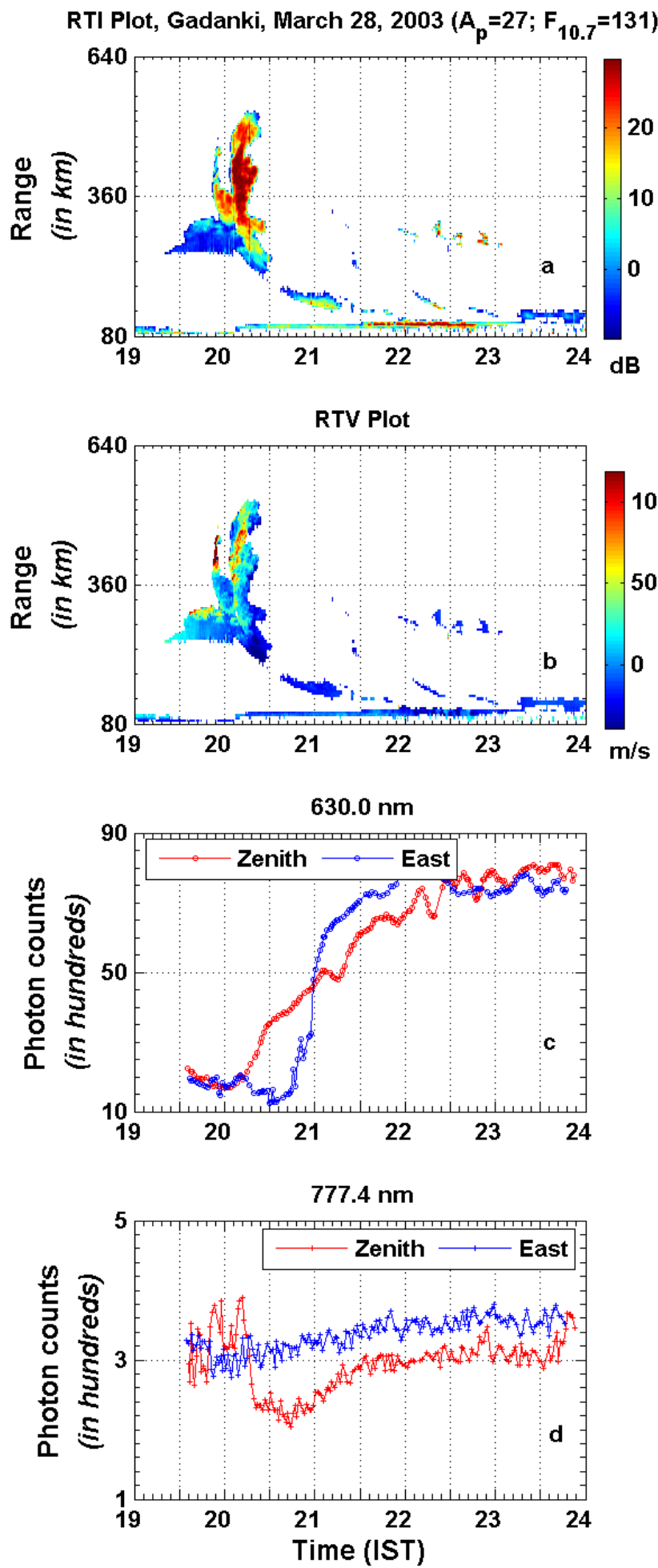

Fig. 6. Similar to Fig. 5 but for 28 March 2003 revealing bottomside ESF structure descending to E-region. Note that the integration time for airglow observations is $1 \mathrm{~s}$.

\subsection{Bottomside ESF structure descending to E-region}

Figure 6 depicts another case of ESF event on 28 March $2003\left(A_{P}=27, F_{10.7}=131\right)$. A large scale bottomside structure with a flat crest region just before 20:00 IST is observed in Fig. 6a. The bottomside structure is found to descend to lower altitudes similar to the previous observation reported by Patra et al. (1997). A couple of plume structures are also seen to override the bottomside structure during 20:0020:20 IST. Figure $6 \mathrm{~b}$ reveals predominantly downward velocity in the bottomside as well as in the plume structures. A steep increase in intensity is observed in the temporal variation of $630.0 \mathrm{~nm}$ intensity (Fig. 6c) particularly in the eastward direction. However, signatures of plume structures are recorded only in $777.4 \mathrm{~nm}$ zenith intensity variations $\sim$ 20:00 IST. Corresponding to small patches between 22:00 to 23:00 IST, irregular variations are observed in $630.0 \mathrm{~nm}$ zenith intensities.

\subsection{Isolated plasma plume structure}

Figure 7 depicts an ESF event on 12 February $2005\left(A_{P}=4\right.$, $F_{10.7}=102$ ) wherein a vertically erect structure extending from $\sim 200 \mathrm{~km}$ to $\sim 425 \mathrm{~km}$ is observed in RTI map which is somewhat separated from the adjoining structure. Radar data are not available after 22:00 IST on this night. It is interesting to note that the velocities inside the first structure are predominantly downward barring a small region wherein the velocities are upward. The vertical airglow emission corresponding to this structure clearly reveals an enhancement in $630.0 \mathrm{~nm}$ and possibly so in $777.4 \mathrm{~nm}$ observation over zenith. This serves as a clear example for a plasma enhancement structure extending upto $450 \mathrm{~km}$. The second structure was broader and the velocities were predominantly upward with corresponding decrease in $630.0 \mathrm{~nm}$ intensity over zenith. The signature for the second structure in $777.4 \mathrm{~nm}$ is not clear. The fluctuations observed in $630.0 \mathrm{~nm}$ intensity after $\sim 22: 15$ IST could not be characterized as the radar observation was not available.

Figure 8 depicts isolated, tower-like ESF structures and a small patch which are observed around 22:00 IST on 20 March $2004\left(A_{P}=12, F_{10.7}=101\right)$ along with corresponding airglow observations. Barring a small narrow channel in the tower-like structure, the velocities are predominantly downward. The narrow channel seems to be depleted region of plasma that does not have corresponding signature in optical emissions. This is probably due to weak structure with smaller spatial extent. Enhancements are observed in $630.0 \mathrm{~nm}$ and $777.4 \mathrm{~nm}$ during the period around 22:00 IST when these ESF structures seemingly advect across the radar field-of-view. 

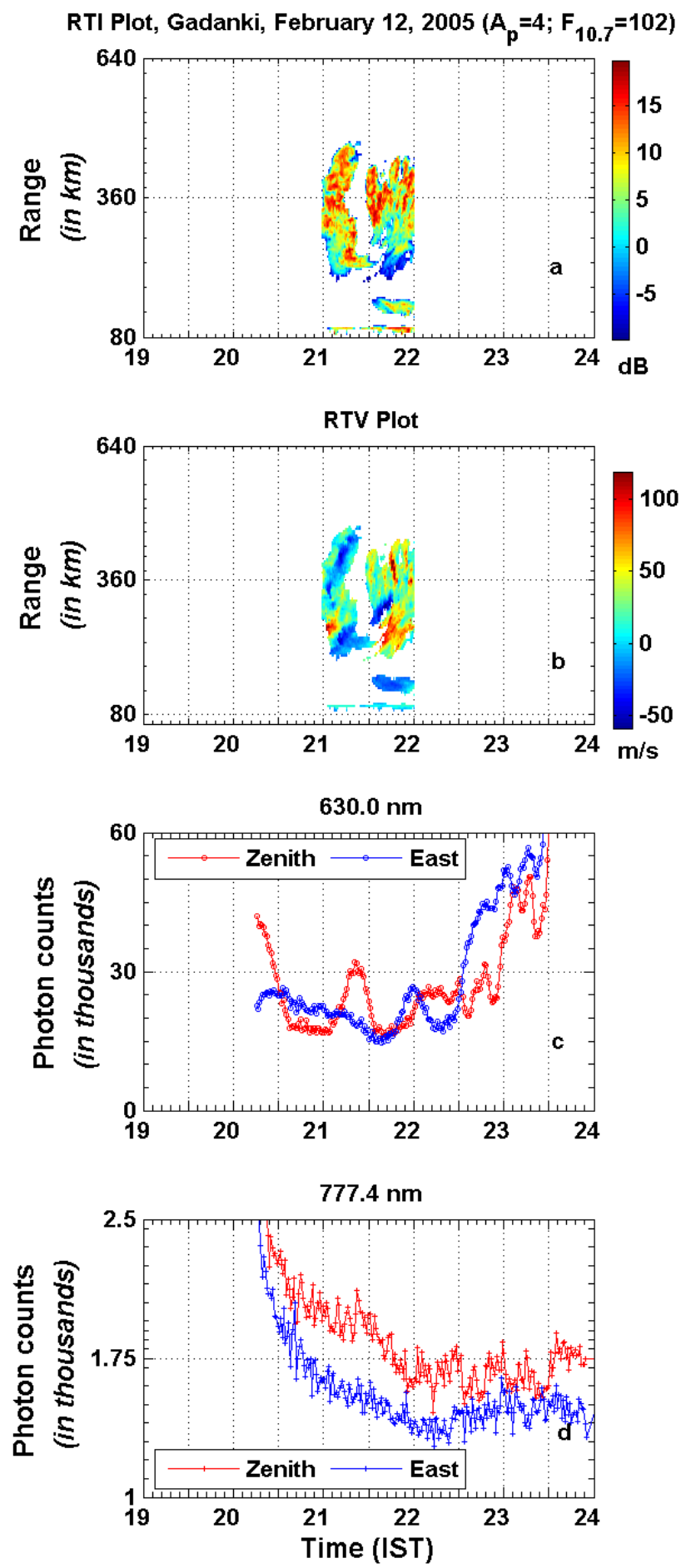

Fig. 7. Similar to Fig. 6 but for 12 February 2005 revealing isolated plasma plume structure. Please note that radar data are available during 21:00-22:00 IST only.

\subsection{Closely-spaced multiple plume structures}

Figure 9 depicts another special event of ESF observed on 6 February $2005\left(A_{P}=10, F_{10.7}=84\right)$. The plasma struc-
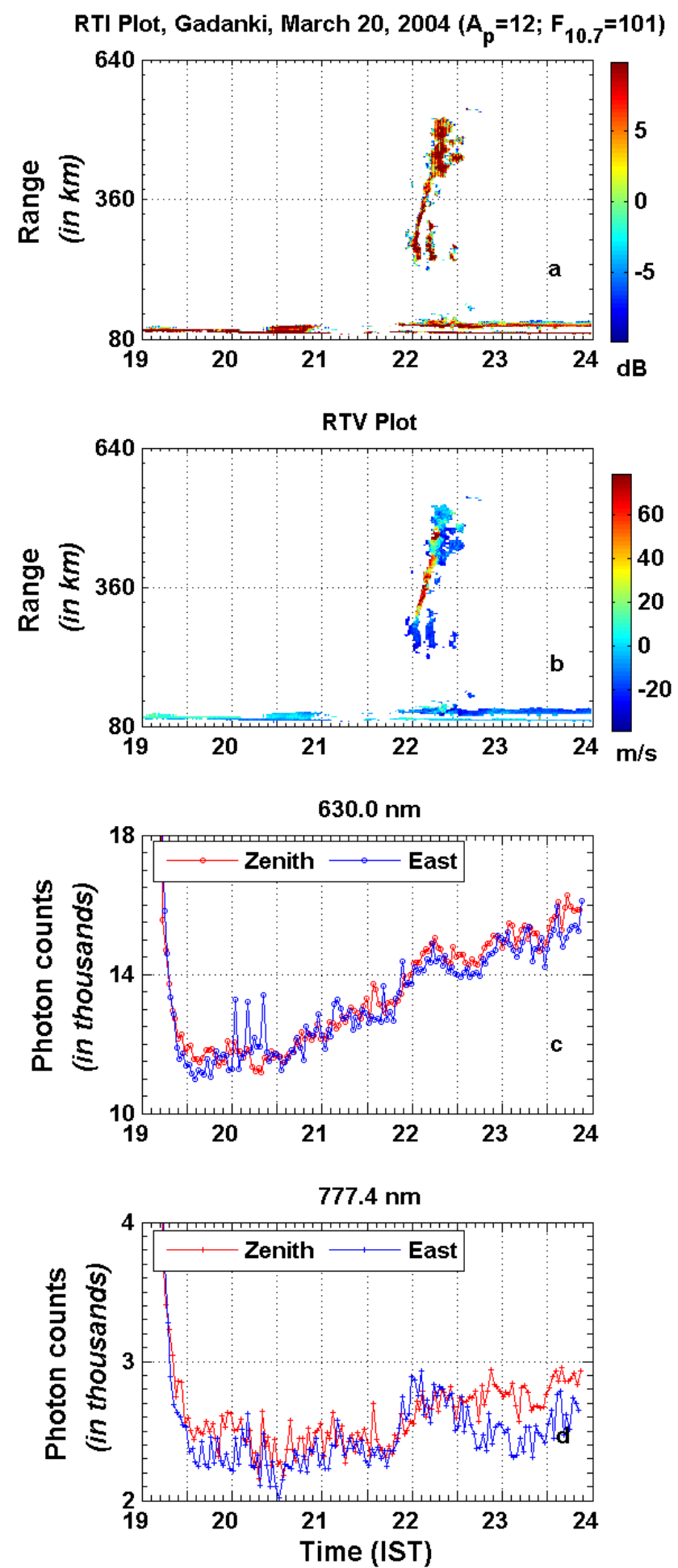

Fig. 8. Similar to Fig. 7 but for 20 March 2004 revealing isolated plasma plume structure.

tures are closely-spaced with peak altitudes not extending above $360 \mathrm{~km}$. The velocities inside these structures are predominantly downward. Comparison of these structures with $630.0 \mathrm{~nm}$ airglow intensity variations reveals that most of 

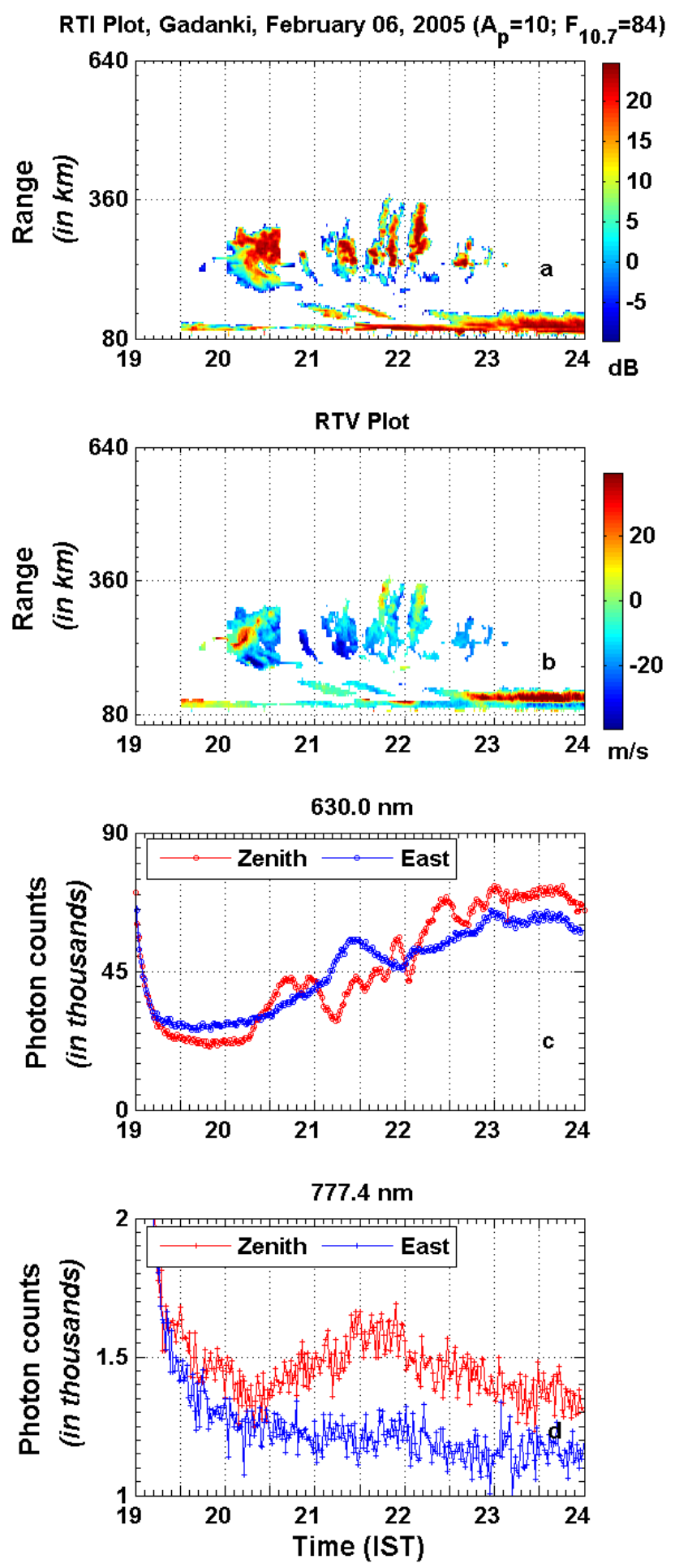

Fig. 9. Similar to Fig. 8 but for 6 February 2005 revealing closelyspaced multiple plume structures.

those structures are plasma enhancements except a structure just after 22:00 IST. Most of the decreases in $630.0 \mathrm{~nm}$ intensity are found to be associated with the absence of plasma enhancement structures associated with ESF. The $777.4 \mathrm{~nm}$ in- tensity does not register any variations corresponding to these ESF structures. However, a broad enhancement observed in $777.4 \mathrm{~nm}$ intensity variation around 21:30 IST over zenith direction. Similar closely-spaced plasma structures (not shown in diagram) during ESF event along with oscillatory features in $630.0 \mathrm{~nm}$ airglow intensities were also recorded on $29 \mathrm{Jan}$ uary $2006\left(A_{P}=2, F_{10.7}=69\right)$.

\subsection{Plasma bubble structure}

Another ESF event obtained on 6 March $2005\left(A_{P}=37\right.$, $\left.F_{10.7}=74\right)$ is depicted in Fig. 10. A bottomside undulation during 20:40-22:30 and a plume structure at around 23:00 IST were observed on this night. The velocities inside this plume structure are predominantly upward. The airglow intensity variations in $630.0 \mathrm{~nm}$ and $777.4 \mathrm{~nm}$ emissions over zenith record unambiguous signatures of plasma depletion around 23:00 IST. The slant columnar intensity variations do not record signatures corresponding to vertically erect depletions. Interestingly, the slant columnar intensity of $777.4 \mathrm{~nm}$ depicted in Fig. 10d is found to be less in comparison with the zenith intensity throughout the period till 23:00 IST.

\section{Discussion}

As mentioned earlier, VHF radar in coherent mode is an important and powerful technique to understand the phenomenon of ESF. This technique is useful to investigate the electron density irregularities present in bottom and topside of the ionosphere. However, using this technique alone, identification of the depleted or enhanced plasma regions unequivocally is not possible, as the return echo strength is proportional to square of electron density fluctuations. It is well known that, in general, the plasma depleted regions move upward and plasma enhancement regions move downward (Ossakow and Chaturvedi, 1978). Thus an indication on the nature of relative plasma densities inside the ESF structures with respect to the background can be obtained from the polarity of the Doppler velocities depicted in RTV maps. However, these indications, on occasions, can mislead as the depleted structures in a decaying phase of ESF evolution were shown (Sekar et al., 2007) to move downward. Thus the velocities inside the ESF structures cannot be used to characterize them unambiguously. As the thermospheric airglow intensity variations are directly proportional to fluctuations in electron densities, co-ordinated airglow measurements are used to identify plasma depletions and enhancements. The signatures provided by the airglow measurements are, thus, complementary with VHF radar measurements making it possible to completely characterize the ESF structures. The present observations reveal upward moving depletions and downward moving enhancements extending even beyond $350 \mathrm{~km}$ altitudes. Earlier simulation analysis (Sekar et al., 2001) brought out the importance of more than 
one wavelength mode as seed perturbations for the generation of plasma enhancement beyond $350 \mathrm{~km}$. The structures depicted in Figs. 1 and 3 indicate in support of this simulation as the plume structures ride over a large scale bottomside structures. Moreover, the phase relation between the intensities of $630.0 \mathrm{~nm}$ observed over east and the intensities of $777.4 \mathrm{~nm}$ over zenith (see Fig. 1) supports the possible phase correlation between the two seeding wavelength modes employed in those simulations (Sekar et al., 2001). On the other hand, the isolated structures without the connection to the bottomside reported in Figs. 7 and 8 require further investigation.

In the absence of steering facility of the existing MST radar at Gadanki, the bi-directional airglow measurements over zenith and eastward directions are used to infer zonal plasma drifts. Identifiable crests and/or troughs in the temporal variations of airglow intensities having mutual correspondences are chosen to infer the trace velocities. By assuming the peak of the emission altitude of $630.0 \mathrm{~nm}$ to be $\sim 250 \mathrm{~km}$ during nighttime, the zonal separation between the mutually corresponding points is $250 \mathrm{~km}$ for the present set of measurements where the elevation angle is $45^{\circ}$. The trace drift velocities in the zonal direction are estimated using the zonal separation and the temporal delay between the corresponding points. It is noticed that the trace velocities on most of the occasions are in eastward direction. The eastward drift velocities were $\sim 116 \mathrm{~m} \mathrm{~s}^{-1}$ and $139 \mathrm{~m} \mathrm{~s}^{-1}$ at $\sim 20: 20$ and 21:30 IST on 25 March 2003 while the velocities decrease from $87 \mathrm{~m} \mathrm{~s}^{-1}$ to $69 \mathrm{~m} \mathrm{~s}^{-1}$ from $\sim 21: 30$ to 22:20 IST on 21 March 2004. The eastward drift velocities on 11 February 2004, 7 and 12 February 2005, were 126, 86 and $116 \mathrm{~m} \mathrm{~s}^{-1}$ respectively at $\sim 20: 30$ IST. These values are in the range of the measured zonal drift over Jicamarca (Fejer, 1981). However, these observations are not adequate to provide systematic temporal variations over Gadanki. It is interesting to note that the trace velocity inferred on 19 March 2004 at 22:00 IST was westward $\left(\sim-116 \mathrm{~m} \mathrm{~s}^{-1}\right)$ around the emission altitude (i.e. $\sim 250 \mathrm{~km}$ ) region as the corresponding points in the temporal variations of $630.0 \mathrm{~nm}$ intensities over eastern direction are preceding the zenith observations (see Fig. 4). However, the reason for the high value of the westward drift is not clear and needs further investigation. Similar such westward velocity on 7 January 2005 was also inferred by Chakrabarty et al. (2006) using similar set of observations, when the plasma structures were confined to a limited altitude region around $250-300 \mathrm{~km}$. However, above $\sim 250 \mathrm{~km}$, the zonal plasma drift is essentially governed by F-region dynamo during nighttime which drives the plasma in the eastward direction. This is mainly due to the eastward wind determined by the thermal gradient in the thermosphere. Thus the inference of westward drift around the altitude emission of $630.0 \mathrm{~nm}$ clearly indicates a strong vertical shear in the zonal plasma drift. These observations are consistent with the earlier numerical simulation of Sekar and Kelley (1998) wherein it was shown that the strong shears
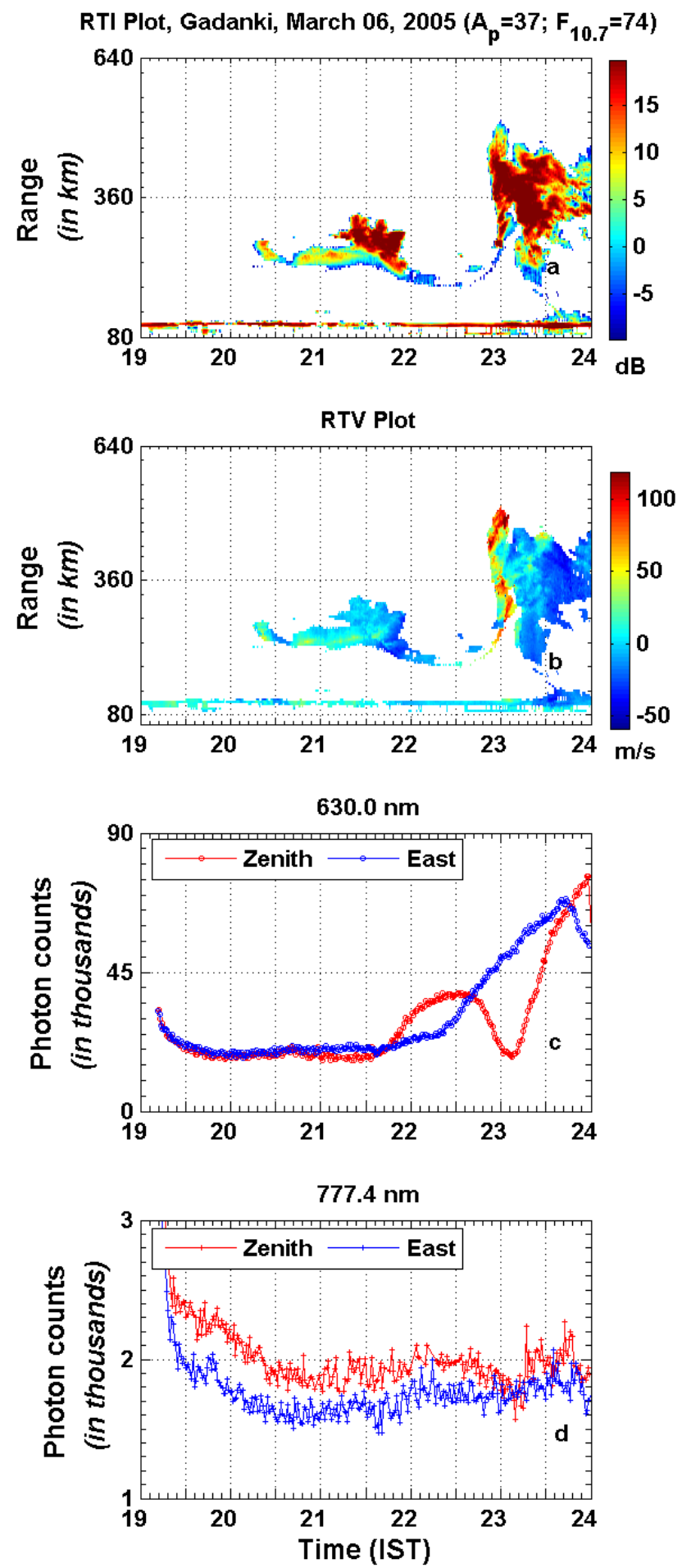

Fig. 10. Similar to Fig. 9 but for 6 March 2005 including the $777.4 \mathrm{~nm}$ observations in the bottom panel. The observations reveal the plasma bubble structure.

in the zonal plasma drift is important to confine the ESF structures in a limited altitude region. However, the confinement structure obtained on 21 March 2004 (Fig. 5) did not 
accompany with the polarity change in zonal plasma drift. Note this does not preclude that there are altitude variations in the eastward plasma drift. Based on the simulation of $\mathrm{Za}$ lesak et al. (1982), it can be inferred that the slanted plume structure around 21:00 IST is a clear indication of altitude variation in the eastward plasma drift.

In the absence of steerable radar, it is difficult to decipher whether the ESF structures observed in RTI maps are due to temporal variations or spatially varying structures moving into the radar field of view by the background zonal drift (Woodman and La Hoz, 1976). Using the scanning capability of the Equatorial Atmosphere Radar, Fukao et al. (2004) have shown that while the ESF structures are advecting horizontally into the radar beam, the structures are also evolving with time. While the uncertainty remain with the finer scale structures, the large scale structures localized in the zonal direction could be taken to represent zonal scale sizes of the ESF structurs. The coordinated airglow and radar measurements provide a way in some cases to determine the spatial scale structures in zonal direction. For example, the zonal wavelength of the bottomside structure observed on 25 March 2003 and depicted in Fig. 3, is $\sim 626 \mathrm{~km}$ considering a trace velocity of $\sim 116 \mathrm{~m} \mathrm{~s}^{-1}$. Similarity in the patterns of zonal and zenith airglow intensity variations confirms the presence of zonal structures. Such a large wave-like bottomside ESF structures with large altitude extents, similar to the observations over Jicamarca (Kelley et al., 1981), have been observed even over Gadanki where dip angle is $15^{\circ} \mathrm{N}$ at Fregion altitudes. Simultaneous measurements from the dip equator and off-equatorial region are required to conclude that such large scale structures are indeed mapped along the magnetic field lines. Some of these wave-like structures encompass both airglow emitting altitude regions where shears alone in the zonal plasma flow with respect to neutrals cannot be a seed. Thus, these structures are in support of that the gravity waves are the seed (Kelley et al., 1981) for such bottomside structures. Further, the presence of such large scale seed perturbations observed on both magnetically quiet and disturbed conditions (refer Figs. 1 to 3) indicates that the auroral activities need not be the source. However, the bottomside large wave-like structures (Figs. 1 and 2) are conspicuously more irregular (presence of fine structures) during the disturbed period compared to quiet time structure (Fig. 3). The role of disturbance electric field to form fine structures within the large bottomside structure needs to be investigated further. In contrast to the large scale wave-like structures, comb-like structures shown in Fig. 9 require much smaller seed wavelengths. Nearly three plumes are observed within an hour in RTI map (see Fig. 9) at a lower altitude region of $\sim 220 \mathrm{~km}$. The trace velocity in the zonal direction is only $\sim 60 \mathrm{~m} \mathrm{~s}^{-1}$ on this night (6 February 2005). Assuming each plume evolved from the trough region of each wave, the zonal wavelength is estimated to be $\sim 72 \mathrm{~km}$. Spatial structures in the electric field generated by E-region gravity waves and mapped from the off-equatorial region are suggested (Huang and Kelley, 1996) to be the possible seed for such plumes. This possibility of off-equatorial E-region electric field structures seeding the ESF structures with smaller wavelength needs to be explored in future. Further, the connection between the upper E-region and the Fregion plasma structure particularly the large scale bottomside structure needs further investigations. Earlier investigation (Sekar et al., 2001) revealed that the electric field generated by the interaction between the large and small scale size perturbations with suitable amplitude can lead to descending structure (Fig. 6) to upper E-region.

The interesting point emerges using bi-directional airglow measurements that the slant columnar airglow intensities, in spite of geometrical advantages, on occasions, are found to be less than the corresponding zenith observations. Many such examples are provided in the results section. This is in contrast to the Van-Rhijn advantage principle based on which the slant columnar intensities are generally expected to be more than the zenith intensities. This can happen in the presence of depleted ESF structures in off-zenith directions and/or enhancement structures over zenith when these structures nearly fill the field of view at the emission altitude region. This is clearly evident in the narrow-beam photometry employed in the present investigation. Photometry with a large field of view (broad-beam) may average out the airglow intensity fluctuations associated with ESF (occupying less spatial region) compared to the background airglow intensity (occupying more spatial region). This makes the slant columnar intensity to exceed the zenith intensity in case of broad-beam photometry. On the otherhand, the narrow beam photometer operated in $45^{\circ}$ eastern direction, on occasion, can underestimate the degree of depletion (see Fig. 10) of a vertically erect plasma depleted structure in the presence of neighbouring plasma enhancement structures owing to the relatively larger contributions of the large background in comparison with the plume structure in the airglow intensity along the slant path. Finally, since the signal to noise ratio for $777.4 \mathrm{~nm}$ airglow intensity is not as high as in $630.0 \mathrm{~nm}$, the signatures in $777.4 \mathrm{~nm}$ are clearly evident only when the $777.4 \mathrm{~nm}$ signal intensities are significant.

Therefore, it is apparent that coordinated optical and radar observation of ESF is a powerful tool to probe the finer features of ESF and to infer many dynamical conditions that govern the evolution of ESF. More such observations are planned to investigate ESF in a comprehensive manner.

\section{Summary}

Based on simultaneous VHF radar measurements with bidirectional scanning, narrow band and narrow beam photometric observations of thermospheric airglow during ESF events, potential science applications in addition to the identifications of plasma depletion (bubble) and enhancement structures are discussed. The wavelengths of large scale 
bottomside structures are estimated using bi-directional airglow observations. Further, the possible shear in the zonal plasma drift is inferred when the ESF structure is confined to limited altitude region. It is found that on occasions, the vertical columnar intensity of OI $630.0 \mathrm{~nm}$ airglow obtained using narrow band photometry exceeded the slant columnar intensity in the presence of large bottomside structures. The need for the physical mechanisms for the development of plasma enhancement structures without the bottomside structures and the seeding of ESF by E-region electric field structures are discussed. The importance of simultaneous measurements from the dip and off-equatorial region for mapping of wavelike bottomside ESF structure with large altitude extents is emphasized.

Acknowledgements. The authors thank the Director and the staff members of the National Atmospheric Research Laboratory for their cooperation in making the observational campaign successful. This work is supported by the Department of Space, Government of India.

Topical Editor M. Pinnock thanks M. Kelley and J. H. Sastri for their help in evaluating this paper.

\section{References}

Chakrabarty, D., Sekar, R., Narayanan, R., Patra, A. K., and Devasia, C. V.: Effects of interplanetary electric field on the development of an equatorial spread-F event, J. Geophys. Res., 111, A12316, doi:10.1029/2006JA011884, 2006.

Fejer, B. G.: The equatorial ionospheric electric fields: A review, J. Atmos. Terr. Phys., 43, 377-386, 1981.

Fukao, S., Ozawa, Y., Yokoyama, T. Yamamoto, Y., and Tsunoda, R. T.: First observations of spatial structure of $\mathrm{F}$ region $3 \mathrm{~m}$ scale field-aligned irregularities with the Equatorial Atmosphere Radar in Indonesia, J. Geophys., Res., 109, A02304, doi:10.1029/2003JA010096.

Huang, C.-S. and Kelley, M. C.: Nonlinear evolution of equatorial spread F 3. Plasma bubbles generated by structured electric fields, J. Geophys. Res., 101, 303-313, 1996.

Kelley, M. C., Larsen, M. F., LaHoz, C., and McClure, J. P.: Gravity wave initiation of equatorial Spread F: A case study, J. Geophys. Res., 86, 9087-9100, 1981.

Kelley, M. C.: The Earths Ionosphere, Int. Geophys. Ser., Academic Press, San Diego, California, 43, 114-119, 1989.

Mendillo, M., Baumgardner, J., Pi. X, Sultan, P. J., and Tsunoda, R.: Onset conditions for equatorial spread F, J. Geophys. Res., 97, 13 865-13 876, 1992.

Ossakow, S. L. and Chaturvedi, P. K.: Morphological studies of rising equatorial spread F bubbles, J. Geophys. Res., 83, 20852090, 1978.
Patra, A. K., Ananadan, V. K., Rao, P. B., and Jain, A. R.: First observations of equatorial spread F from Indian MST radar, Radio Sci., 30, 1159-1165, 1995.

Patra, A. K., Rao, P. B., Anandan, V. K., and Jain, A. R.: Radar observations of $2.8 \mathrm{~m}$ equatorial spread $\mathrm{F}$ irregularities, J. Atmos. Sol-Terr. Phys., 59, 1633-1641, 1997.

Rao, P. B., Jain, A. R., Kishore, P., Balmuralidhar, P., Damle, S. H., and Vishwanathan, G.: Indian MST radar, system description and sample vector wind measurements in ST mode, Radio Sci., 30, 1125-1138, 1995.

Rino, C. L., Tsunoda, R. T., Petriceks, J., Livingston, R. C., Kelley, M. C., and Baker, K. D.: Simultaneous rocket-borne beacon and in-situ measurements of equatorial spread F-intermediate wavelength results, J. Geophys. Res., 86, 2411-2420, 1981.

Sekar, R. and Kelley, M. C.: On the combined effects of vertical shear and zonal electric field patterns on nonlinear equatorial spread F evolution, J. Geophys. Res., 103, 20 735-20 747, 1998.

Sekar, R., Kherani, E. A., Rao, P. B., and Patra, A. K.: Interaction of two long wavelength modes in the non-linear numerical simulation model of equatorial Spread-F, J. Geophys. Res., 106(A11), 24 765-24 775, 2001.

Sekar, R., Chakrabarty, D., Narayanan, R., Sripathy, S., Patra, A. K., and Subbarao, K. S. V.: Characterization of VHF radar observations associated with equatorial Spread F by narrow-band optical measurements, Ann. Geophys., 22, 3129-3136, 2004, http://www.ann-geophys.net/22/3129/2004/.

Sekar, R., Chakrabarty, D., Sarkhel, S., Patra, A. K., Devasia, C. V., and Kelley, M. C.: Identification of active fossil bubbles based on coordinated VHF radar and airglow measurements, Ann. Geophys., 25, 2099-2102, 2007, http://www.ann-geophys.net/25/2099/2007/.

Sekar, R. and Chakrabarty, D.: Role of overshielding electric field on the development of premidnight plume event: simulation results, J. Atmos. Sol-Terr. Phys., 70, 2212-2221, 2008.

Tsunoda, R. T. and Towle, D. M.: On the spatial relationship of 1-meter equatorial spread $\mathrm{F}$ irregularities and depletions in total electron content, Geophys. Res. Lett., 6, 873-876, 1979.

Tsunoda, R. T.: Magnetic field-aligned characteristic of plasma bubbles in the night time equatorial ionosphere, J. Atmos. Terr. Phys., 42, 743-752, 1980.

Tsunoda, R. T., Livingston, R. C., McClure, J. P., and Hanson, W. B.: Equatorial plasma bubbles vertically elongated wedges from the bottomside F layer, J. Geophys. Res., 87, 9171-9180, 1982.

Weber, E. J., Basu, S., Bullett, T. W., et al.: Equatorial plasma depletion precursor signatures and onset observed at $11^{\circ}$ south of the magnetic equator, J. Geophys. Res., 101(A12), 2682926838, 1996.

Woodman, R. F. and La Hoz, C.: Radar observations of F region equatorial irregularities, J. Geophys. Res., 81, 5447-5466, 1976.

Zalesak, S. T., Ossakow, S. L., and Chaturvedi, P. K.: Nonlinear equatorial spread F; The effects of neutral winds and background conductivity, J. Geophys. Res., 87, 151-166, 1982. 